\title{
Crystal Structure of Manganese(III) Hydrogen Selenite Diselenite, $\mathrm{MnH}\left(\mathrm{SeO}_{3}\right)\left(\mathrm{Se}_{2} \mathrm{O}_{5}\right)$
}

\author{
MARKUS KOSKENLINNA and JUSSI VALKONEN
}

Department of Chemistry, Helsinki University of Technology, Otaniemi, SF-02150 Espoo 15, Finland

The crystal structure of manganese(III) hydrogen selenite diselenite, $\mathrm{MnH}\left(\mathrm{SeO}_{3}\right)\left(\mathrm{Se}_{2} \mathrm{O}_{5}\right)$, has been determined by $\mathrm{X}$-ray methods. The compound is monoclinic, and belongs to the space group $P 2_{1} / n$ with $Z=4$. The cell dimensions are $a=7.451(2) \AA, b=12.583(4) \AA, c=$ $7.575(2) \AA$ and $\beta=92.82(2)^{\circ}$. The structure was solved by direct methods, and refined to $\boldsymbol{R}=\mathbf{0 . 0 3 5}$.

The $\mathrm{MnO}_{6}$-octahedron is distorted by Jahn. Teller forces, with $\mathrm{Mn}-\mathrm{O}$ bonds ranging from $1.916 \AA$ to $2.179 \AA$. The compound contains both selenite and diselenite groups, which act as bridging ligands between two and three $\mathbf{M n}$ atoms, respectively. The $\mathrm{Se}-\mathrm{O}$ bonds range between 1.662 and $1.776 \AA$ in the selenite and between 1.664 and $1.803 \AA$ in the diselenite group.

The structural features of $\mathrm{Mn}$ (III) compounds are of interest because of the high spin $d^{4}$. configuration leading to Jahn-Teller distortions of the coordination polyhedron around the central atom. As a part of our studies on the manganese selenites we described the preparation and structure of $\mathrm{Mn}_{2}\left(\mathrm{SeO}_{3}\right)_{2} \cdot 3 \mathrm{H}_{2} \mathrm{O}$, a compound having tetragonally elongated $\mathrm{MnO}_{6}$-octahedra. ${ }^{1}$ Recently it was found that a praseodymium compound with both a selenite and a diselenite group as a ligand could be prepared.2 We report now the preparation and structure of $\mathrm{MnH}\left(\mathrm{SeO}_{3}\right)\left(\mathrm{Se}_{2} \mathrm{O}_{5}\right)$.

\section{EXPERIMENTAL}

Manganese(III) hydrogen selenite diselenite, $\mathrm{MnH}\left(\mathrm{SeO}_{3}\right)\left(\mathrm{Se}_{2} \mathrm{O}_{5}\right)$, was prepared in two stages. First, freshly precipitated, hydrated manganese dioxide and a concentrated solution (1 $\mathrm{mol} / \mathrm{dm}^{3}$ ) of selenous acid were placed in a steel reactor with Teflon lining, and the suspension was held at $140^{\circ} \mathrm{C}$ for $1-3$ weeks. A red, amorphous manganese selenite precip. itation was obtained. This was filtered off and placed a second time in the reactor at $140^{\circ} \mathrm{C}$, with an excess of $1 \mathrm{~mol} / \mathrm{dm}^{3}$ selenous acid. The tightness of the sealing of the reactor was so adjusted that all the water was able to escape within 2-3 days and thus the $\mathrm{SeO}_{2}$ concentration was gradually increased. When the resulting white mass consisting mainly of $\mathrm{SeO}_{2}$ was extracted with water, the dark-red, lustrous, well-developed prisms of $\mathrm{MnH}\left(\mathrm{SeO}_{3}\right)$ $\left(\mathrm{Se}_{8} \mathrm{O}_{5}\right)$ remained in the residue.

The intensities of 1366 reflections with $I>3 \sigma$ (I) were measured between $5^{\circ}<2 \theta<55^{\circ}$ in a $\theta-2 \theta$ scan, using a Syntex $P 2_{1}$ (fortran version) automatic four-circle diffractometer and graphite monochromatized MoK $\alpha$-radiation. The scan speed was $2^{\circ} / \mathrm{min}$. The size of the crystal was approximately $0.2 \times 0.2 \times 0.2$ $\mathrm{mm}^{3}$. The unit cell dimensions were obtained by measuring 25 independent reflections from the random-orientation rotation photograph and centering their positional parameters with the diffractometer. The unit cell dimensions for the selected set of axes are, after leastsquares treatment $a=7.451(2) \AA, b=12.583(4)$ $\AA, c=7.575(2) \AA$ and $\beta=92.82(2)^{\circ}$ and the unit cell belongs to the space group $P 2_{1} / n$ according to the systematic absences $h 0 l$ with $h+l=2 n+1$ and $0 k 0$ with $k=2 n+1$. Calculated density for the crystals was $3.94 \mathrm{~g} / \mathrm{cm}^{3}$. There are four formula units in the unit cell. Lorentz, polarization and empirical absorption corrections (from the $\phi$-scan data, $\mu=170.5 \mathrm{~cm}^{-1}$ ) were applied to the data.

Neutral atoms were presumed in the solving and refinement of the structure and the values for their scattering factors were obtained from the International Tables..$^{8}$ All the calculations were performed on a Univac 1108 computer using the X-Ray 1976 program package. The structure was solved by direct methods with $208 E$-values bigger than 1.4. The $E$-map gave the sites of the Se and Mn atoms. These were then refined to an $R$ of $\mathbf{1 7 . 9 \%}$, and the subse- 
Table 1. Atomic coordinates and anisotropic temperature coefficients with their estimated standard deviations. The temperature coefficients are of the form $\exp \left[-2 \pi^{2}\left(h^{2} a^{* 2} U_{11}+k^{2} b^{* 2} U_{32}+l^{2} c^{* 2} U_{33}+2 h k a^{*} b^{*} U_{12}\right.\right.$ $\left.\left.+2 h l a * c * U_{13}+2 k l b * c * U_{2 s}\right)\right]$, and have been multiplied by $10^{4}$.

\begin{tabular}{lllllllrrr}
\hline Atom & $x$ & $y$ & $z$ & $U_{11}$ & $U_{22}$ & \multicolumn{1}{l}{$U_{33}$} & \multicolumn{1}{c}{$U_{12}$} & \multicolumn{1}{c}{$U_{13}$} & $U_{23}$ \\
\hline Mn & $.4387(2)$ & $.6792(1)$ & $.3055(2)$ & $80(6)$ & $53(6)$ & $68(6)$ & $6(5)$ & $15(5)$ & $5(5)$ \\
Sel & $.0520(1)$ & $.7988(1)$ & $.3869(1)$ & $107(4)$ & $84(4)$ & $90(4)$ & $18(3)$ & $27(3)$ & $10(3)$ \\
Se2 & $.0668(1)$ & $.6330(1)$ & $.0677(1)$ & $109(4)$ & $\mathbf{8 5}(4)$ & $94(4)$ & $-13(3)$ & $5(3)$ & $-1(3)$ \\
Se3 & $.7258(1)$ & $.5148(1)$ & $.4281(1)$ & $109(1)$ & $78(4)$ & $128(4)$ & $11(3)$ & $16(3)$ & $7(3)$ \\
O1 & $.5337(9)$ & $.7647(6)$ & $.0780(8)$ & $187(36)$ & $128(34)$ & $95(31)$ & $-53(28)$ & $48(26)$ & $-25(26)$ \\
O2 & $.2742(9)$ & $.7930(6)$ & $.3440(9)$ & $121(32)$ & $107(32)$ & $189(34)$ & $-8(27)$ & $47(26)$ & $-19(28)$ \\
O3 & $.2667(9)$ & $.5970(6)$ & $.1577(10)$ & $139(34)$ & $117(33)$ & $204(36)$ & $27(27)$ & $-11(28)$ & $8(28)$ \\
O4 & $.6222(9)$ & $.7603(6)$ & $.4510(9)$ & $115(32)$ & $181(35)$ & $97(31)$ & $48(27)$ & $15(25)$ & $42(27)$ \\
O5 & $.8891(10)$ & $.0720(6)$ & $.2466(9)$ & $178(35)$ & $165(36)$ & $87(31)$ & $-59(29)$ & $47(26)$ & $21(27)$ \\
O6 & $.6099(10)$ & $.4040(6)$ & $.4583(9)$ & $198(36)$ & $107(33)$ & $143(33)$ & $34(28)$ & $54(27)$ & $79(27)$ \\
O7 & $.6001(11)$ & $.9606(6)$ & $.1963(11)$ & $247(42)$ & $155(38)$ & $328(45)$ & $-57(32)$ & $148(35)$ & $-82(33)$ \\
O8 & $.5384(10)$ & $.1930(6)$ & $.2511(9)$ & $158(34)$ & $268(42)$ & $129(33)$ & $50(31)$ & $67(27)$ & $46(31)$ \\
\hline
\end{tabular}

Table 2. Selected bond distances $(\AA)$ and angles $\left({ }^{\circ}\right)$. The estimated standard deviations are in parentheses.

\begin{tabular}{|c|c|c|c|c|c|}
\hline $\begin{array}{l}M n-01 \\
M n-O 2 \\
M n-03 \\
M n-04 \\
M n-05 \\
M n-06\end{array}$ & $\begin{array}{l}2.179(7) \\
1.916(7) \\
1.956(7) \\
1.994(7) \\
1.916(7) \\
2.119(7)\end{array}$ & $\begin{array}{l}\mathrm{Sel}-\mathrm{O} 1 \\
\mathrm{Sel}-\mathrm{O2} \\
\mathrm{Se} 1-\mathrm{O} 8 \\
\mathrm{Se2}-\mathrm{O8} \\
\mathrm{Se2}-\mathrm{O3} \\
\mathrm{Se2}-\mathrm{O4}\end{array}$ & $\begin{array}{l}1.664(7) \\
1.705(7) \\
1.803(8) \\
1.781(8) \\
1.670(7) \\
1.671(7)\end{array}$ & $\begin{array}{l}\mathrm{O} 1-\mathrm{Sel}-\mathrm{O} 2 \\
\mathrm{O} 1-\mathrm{Sel}-\mathrm{O} 8 \\
\mathrm{O} 2-\mathrm{Se} 1-\mathrm{O} 8 \\
\mathrm{O} 8-\mathrm{Se} 2-\mathrm{O} 3 \\
\mathrm{O} 8-\mathrm{Se2}-\mathrm{O} 4 \\
\mathrm{O} 3-\mathrm{Se} 2-\mathrm{O} 4 \\
\mathrm{Se} 1-\mathrm{O} 8-\mathrm{Se} 2\end{array}$ & $\begin{array}{r}105.5(3) \\
96.1(3) \\
101.3(3) \\
102.6(3) \\
101.4(4) \\
101.3(3) \\
126.4(4)\end{array}$ \\
\hline $\begin{array}{l}O 1-M n-06 \\
O 2-M n-O 5 \\
O 3-M n-04 \\
O 1-M n-03 \\
O 4-M n-O 5 \\
O 2-M n-06\end{array}$ & $\begin{array}{r}170.8(3) \\
175.7(3) \\
177.7(3) \\
92.2(3) \\
91.5(3) \\
95.9(3)\end{array}$ & $\begin{array}{l}\mathrm{Se3}-\mathrm{O5} \\
\mathrm{Se3}-\mathrm{O6} \\
\mathrm{Se} 3-\mathrm{O} 7\end{array}$ & $\begin{array}{l}1.700(7) \\
1.662(7) \\
1.776(8)\end{array}$ & $\begin{array}{l}\mathrm{O} 5-\mathrm{Se} 3-\mathrm{O} 6 \\
\mathrm{O} 5-\mathrm{Se} 3-\mathrm{O} 7 \\
\mathrm{O} 6-\mathrm{Se} 3-\mathrm{O} 7\end{array}$ & $\begin{array}{r}102.5(3) \\
95.9(4) \\
98.6(4)\end{array}$ \\
\hline
\end{tabular}

quent difference Fourier map revealed the sites of all the $O$ atoms. After refinement with isotropic temperature factors the value of $R$ was $4.3 \%$, and with anisotropic temperature factors, after block-diagonal refinement, $3.5 \%$.

The $\left|F_{\mathrm{o}}\right|$ and $\left|F_{\mathrm{c}}\right|$ listing is available from the authors upon request.

\section{DISCUSSION}

The atomic coordinates and anisotropic temperature coefficients are given in Table 1. The seleniums Sel and $\mathrm{Se} 2$ belong to a disele. nite ion and Se3 to a selenite ion. In Table 2 some characteristic bond lengths and angles are given.

The compound contains both selenite and diselenite groups. One of the $\mathrm{Se}-\mathrm{O}$ bonds in the selenite group is significantly longer, 1.776(8)
$\AA$, than the other two, suggesting a hydrogen bridge. Similar stretching was detected in $\mathrm{PrH}_{3}\left(\mathrm{SeO}_{3}\right)_{2}\left(\mathrm{Se}_{2} \mathrm{O}_{5}\right)$, in which the $\mathrm{Se}-\mathrm{O}$ bonds of the two non-equivalent selenite groups lie in the range $1.624(14)-1.656(16) \AA$ and 1.766(16) - 1.805(18) $\AA$ for $\mathrm{Se}-\mathrm{O}$ and $\mathrm{Se}-\mathrm{OH}$ bonds, respectively.2 The selenite group acts as a bridging ligand between two $\mathrm{Mn}$ atoms, and the $\mathrm{Se}$ links the apical oxygen of one octahedron to the equatorial oxygen of another.

The geometry of the diselenite group is like that of several other diselenite compounds. However, the bonds to the oxygen bridging the two Se atoms are slightly shorter than usual: $1.781(8)$ and $1.803(8) \AA$, compared with 1.835 and $1.847 \AA$ in $\mathrm{PrH}_{3}\left(\mathrm{SeO}_{3}\right)_{2}\left(\mathrm{Se}_{2} \mathrm{O}_{5}\right)$, $1.831 \AA$ in $\mathrm{MnSe}_{2} \mathrm{O}_{5}, 1.831 \AA$ in $\mathrm{CuSe}_{2} \mathrm{O}_{5}$, 1.768 and $1.822 \AA$ in $\mathrm{VSe}_{2} \mathrm{O}_{6}$ and $1.827 \AA$ in Acta Chem. Scand. A 31 (1977) No. 8 
$\mathrm{ZnSe}_{2} \mathrm{O}_{5} \cdot{ }^{2,}$, 6-8 The ion is also less bent than usual. The angle $\mathrm{Sel}-\mathrm{O8}-\mathrm{Se} 2$ is $126.4(4)^{\circ}$, which may well be a consequence of the short $\mathrm{Se}-\mathrm{O}$ bond lengths: if the angle were $120^{\circ}$, the $\mathrm{Se}-\mathrm{O}$ bonds would be of the order $1.84 \AA$, with a fixed $\mathrm{Se} 1-\mathrm{Se} 2$ distance. In the other diselenites the corresponding bond angles range between 119.6 and $123.8^{\circ}$. Four of the oxygens in the $\mathrm{Se}_{2} \mathrm{O}_{5}^{2-}$-ion are within bonding distance of three $\mathrm{Mn}$ atoms, and the ion acts as a bridging ligand between them (cf. Fig. 1). Two of the oxygens are coordinated to the same Mn, and are on the equatorial plane of the octahedron. The third oxygen, $\mathrm{O} 2$, is on the equatorial plane of another $\mathrm{MnO}_{6}$-octahedron, and the fourth one, O1, forms the apical oxygen of yet another $\mathrm{MnO}_{\mathrm{s}}$ - octahedron. Thus, the two apical oxygens of the octahedron are from different groups, one being contributed by the diselenite group and the other by the selenite group. One of the equatorial oxygens, O5, is also different from the others: it belongs to a selenite group, while the other three belong to diselenite groups. These differences are reflected in the $\mathrm{Mn}-\mathrm{O}$ distances.

The coordination polyhedron around $\mathbf{M n}$ is distorted as expected. Two of the $\mathrm{Mn}-\mathrm{O}$ bond distances are noticeably larger than the

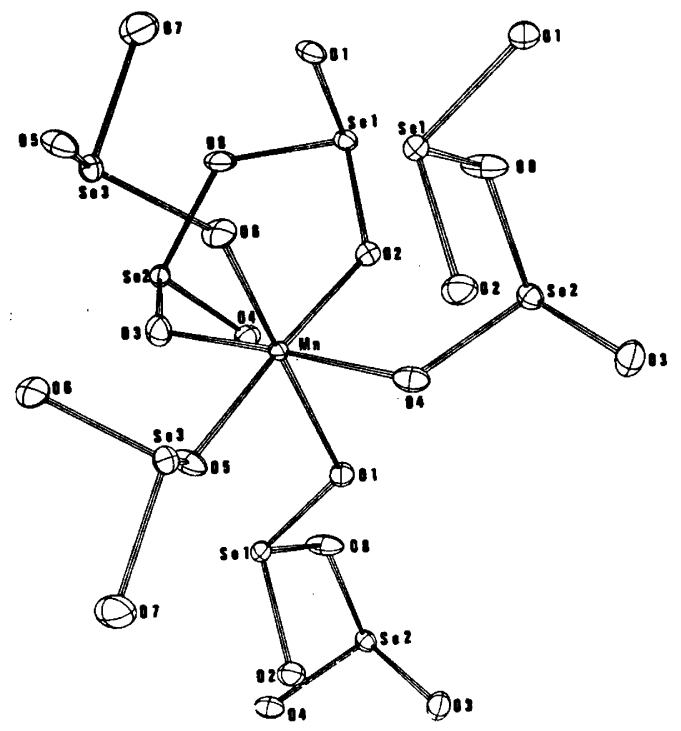

Fig. 1. Bonding scheme of selenite and diselenite groups in $\mathrm{MnH}\left(\mathrm{SeO}_{3}\right)\left(\mathrm{Se}_{2} \mathrm{O}_{5}\right)$. other four. Since the difference between the extreme values within the four shorter bond distances is more than 11 times the corresponding estimated standard deviation, they are not statistically of equal length. The bonds can be arranged into pairs of like magnitude (O1 and 06, 03 and 04,02 and 05 ) with the bonds of each pair situated on opposite sides of the central atoms. The distorted polyhedron thus approximates an orthorhombically distorted octahedron.

The distorted $\mathrm{MnO}_{6}$-octahedra in $\mathrm{Mn}_{2}\left(\mathrm{SeO}_{3}\right)_{3}$. $3 \mathrm{H}_{2} \mathrm{O}$ offer an interesting comparison. One of the three non-equivalent octahedra is tetragonally elongated and two are orthorhombically distorted. The range of bond lengths in the equatorial plane is $1.891(9)-1.938(9) \AA$ and in the axial direction, when the apical oxygens are contributed by water molecules, $2.248(10)-$ 2.346(10) $\AA$. $^{1}$ It is most interesting to note that the one apical oxygen belonging to a selenite group has a shorter $\mathrm{Mn}-\mathrm{O}$ bond length of $2.140(9) \AA$, a value quite compatible with those obtained in the present work $(2.119(7)-2.179(7)$ A). Thus, in $\mathrm{Mn}_{2}\left(\mathrm{SeO}_{3}\right)_{3} \cdot 3 \mathrm{H}_{2} \mathrm{O}$, hydrogen bond formation stretches the $\mathrm{Mn}-\mathrm{O}$ bonds in the axial direction markedly.

\section{REFERENCES}

1. Koskenlinna, M. and Valkonen, J. Acta Chem. Scand. A 31 (1977) 611 .

2. Koskenlinna, M. and Valkonen, J. Acta Chem. Scand. A 31 (1977) 453.

3. International Tables for $X$-Ray Crystallography, Kynoch Press, Birmingham 1974, Vol. 4, p. 72.

4. The X-Ray System, Version of 1976, Steward, J. M. Ed., Technical Report TR-446 of the Computer Science Center, University of Maryland, College Park, Maryland.

5. Koskenlinna, M., Niinistö, L. and Valkonen, J. Acta Chem. Scand. A 30 (1976) 836.

6. Meunier, P., Svensson, C. and Carpy, A. Acta Crystallogr. B 32 (1976) 2664.

7. Meunier, P., Bertand, M. and Galy, J. Acta Crystallogr. B 30 (1974) 2834.

8. Meunier, P. and Bertand, M. Acta Crystal. logr. $B 30$ (1974) 2840.

Received May 9, 1977. 